\title{
Attraction of Planococcus ficus males to racemic and chiral pheromone baits: flight activity and bait longevity
}

\author{
A. Zada ${ }^{1}$, E. Dunkelblum ${ }^{1}$, F. Assael ${ }^{1, \star}$, J. C. Franco ${ }^{2}$, E. B. da Silva ${ }^{2}$, A. Protasov $^{1}$ \& Z. Mendel ${ }^{1}$ \\ 1 Department of Entomology, Volcani Center, ARO, Bet Dagan, Israel \\ 2 Departamento de Proteç̧ão de Plantas e de Fitoecologia, Instituto Superior de Agronomia, Universidade Técnica de Lisboa, Lisboa, Portugal
}

\begin{abstract}
Keywords
Planococcus ficus, enantiomeric activity, pheromone, seasonal and daily flight

\section{Correspondence}

A. Zada, Department of Entomology, Volcani Center, ARO, Bet Dagan 50250, Israel.

E-mail: anatzada@volcani.agri.gov.il

*The author Fabianne Assael deceased on March 3, 2007
\end{abstract}

Received: July 22, 2007; accepted: January 2, 2008

doi: 10.1111/j.1439-0418.2008.01277.x

\begin{abstract}
The vine mealybug (VM), Planococcus ficus (Signoret), is a worldwide pest and affects mainly grapevine and figs. In Israel, (S)-lavandulyl senecioate [(S)-LS] and (S)-lavandulyl isovalerate [(S)-LI] were identified from VM reared for several generations on potato sprouts, when compared with the identification of only (S)-LS from feral females. Racemic lavandulyl senecioate (LS) can be used for fieldwork because the unnatural enantiomer is benign and does not affect the activity of the pheromone. Lures loaded with $200 \mu \mathrm{g}$ of LS remained active for 24 weeks but it is recommended to replace lures after 12 weeks to preserve constant and high attractiveness. Delta sticky traps, baited with 50 or $200 \mu \mathrm{g}$ of LS were used to determine the daily flight pattern and the seasonal flight activity including vine plant infestation. A positive correlation between peak mealybug density and male capture was observed strengthening the usefulness of the pheromone traps for monitoring the pest. Addition of racemic or the two enantiomers of lavandulyl isovalerate (LI) to LS decreased the capture of VM males. The level of inhibition varied during 2003-2004. Both enantiomers of LI displayed the same antagonistic activity. Addition of (S)-lavandulol to the pheromone resulted in shutdown of the traps. Inhibition by the antipode, (R)-lavandulol, was moderate indicating a certain degree of chiral discrimination.
\end{abstract}

\section{Introduction}

The vine mealybug (VM), Planococcus ficus (Signoret), is an Afrotropical species, whose worldwide populations probably originated from the Mediterranean basin. It was introduced to the Americas during the second half of the 20th century (Ben-Dov 1994; Gill 1994). Until the early 1980s, this pest was frequently misidentified as the citrus mealybug, Planococcus citri (Risso), as both Planoccocus spp. are morphologically very similar (Cox 1989). The sex pheromone of VM was identified as (S)-lavandulyl senecioate [(S)-LS] (Hinkens et al. 2001), further stressing the distinction between the latter species and $P$. citri whose sex pheromone is (1R)-cis-2,2-dimethyl-3-isopropenylcyclobutanemethanol acetate (Bierl-Leonhardt et al. 1981).
The VM was collected from plants of 12 families (Ben-Dov 1994). In the Mediterranean, it reach high densities on grapevine (Vitis vinifera) and fig (Ficus carica), while both hosts are infested also by $P$. citri. VM cause direct damage by colonizing grape bunches, soiling them with a mixture of honeydew, sooty mold and scale bodies (Zehavi 2005). The mealybug also transmits grape viral diseases which deteriorate the heath of the vines and lower the quality of grapes (Tanne et al. 1989). Fruit moths, vinegar flies and fungal diseases cause further injury and the infested stem and arms accelerate the damage caused by the caterpillars of carpenter moths (Z. Mendel, A. Protasov and S. Ben Yehuda, unpublished data).

Despite the rich fauna of natural enemies in Israeli vineyards, a satisfactory control of VM populations is 
not often achieved (Mendel and Blumberg 2002). For decades, mealybug populations were kept at low level on the foliage and the grapes due to heavy applications of organophosphates and pyrethroids used against the vineyard key pests: the grape berry moth, Lobesia botrana Den. \& Schiff. (Tortricidae) and the honeydew moth, Cryptoblabes gnidiela (Milliere) (Pyralidae) (Baum 1986). These non-selective insecticides were successfully replaced by mating disruption with pheromone dispensers (Gordon et al. 2005; Harari et al. 2007). Consequently, VM has been managed by systemic neonicotenoid insecticides, mainly imidacloprid, which until lately have kept the mealybug populations at low level (Avisar 2000; Zehavi 2005). However, these insecticides are loosing their efficacy (T. Zehavi, pers. commun.). As a result of what seemed to be a satisfactory situation of the VM, no effort was undertaken to generate information on the population dynamics of the mealybug in vineyards of central and north parts of Israel which might have been helpful in controlling the pest. Recently, pheromone-based management tools have been developed and tested for the control of the VM in California (Millar et al. 2002; Walton et al. 2004, 2006; Daane et al. 2006), due to the shortcomings of the routine management and the inefficient biological control of the pest.

In Israel, (S)-LS and (S)-lavandulyl isovalerate [(S)-LI] were identified from VM reared for several generations on potato sprouts, when compared with the identification of only (S)-LS from field collected females (Zada et al. 2003). In laboratory and field bioassays alike (using racemic compounds), feral males responded only to LS while laboratory reared males responded to both compounds LS and LI (Zada et al. 2003). However, our recent findings indicate that in some vineyards, males are also attracted to LI, although usually in low percentages (Kol-Mimon et al. 2007; Mendel et al., unpublished results).

In the present study, we investigated several aspects of the VM population behaviour with emphasis on male attraction to pheromone lures. We studied the daily and the seasonal flight pattern of the males when compared with the actual infestation of the vines in commercial vineyards. We also examined the longevity of pheromone dispensers. Our recent successful enzymatic separation of racemic lavandulol (Zada and Harel 2004; Zada and Dunkelblum 2006) enabled us to assess the response of VM males in the field to the two enantioenriched pheromone components and lavandulol.

\section{Materials and Methods}

\section{Traps and lures}

Delta traps, with a $16 \times 9.5-\mathrm{cm}$ sticky plate covered on its upper face with glue placed at the bottom of the trap, were used in all field tests, except the daily flight pattern experiment in Portugal. American grey rubber septa (West Co., PA) were used in the daily flight pattern and lure longevity experiments. In all other tests, Israeli rubber dispensers (Yogev Ltd, Rishon LeZion, Israel) were employed. Lures were loaded with hexane solutions of racemic and chiral pheromone components; control lures contained hexane only. Traps were suspended at $1-1.5 \mathrm{~m}$ above ground on the tutor wire of grapevines, approximately $25 \mathrm{~m}$ apart, in a random fashion. The trapped insects were examined in the laboratory in $20 \times$ magnification.

\section{Chemicals}

The racemic pheromone components, lavandulyl senecioate (LS) and lavandulyl isovalerate (LI), were prepared from commercial racemic lavandulol (Fluka, Buchs SG, Switzerland) according to Zada et al. 2003; The two enantiomers of LS, (R)-LS and (S)-LS, and of LI, (R)-LI and (S)-LI, were prepared from $\mathrm{R}$ - and S-lavandulols. The enantiomeric purity of (S)LS and (S)-LI was 95-96\% and of (R)-LS and (R)-LI was $98-99 \%$. The purity of the chiral esters is based on the enatiomeric purity of the chiral isomers of lavandulol which were obtained by an enzymatic resolution of racemic lavandulol (Zada and Harel 2004; Zada and Dunkelblum 2006) and subsequent esterification (Zada et al. 2003). The abbreviated notations LS and LI for the racemic pheromone components and (R)-LS, (R)-LI, (S)-LS and (S)-LI for the chiral components will be used throughout the article.

\section{Longevity of lures}

Lures loaded with $200 \mu \mathrm{g}$ of the LS were aged under ambient conditions, in shade and partially protected from the wind (similar conditions prevail in the vineyards), for 1 day and for $4,8,12,14,16,18,20$, 22 and 24 weeks. The field test was conducted in a 3-year-old vineyard of Syra variety in the Southern Golan, Israel, with a moderate to heavy infestation. The traps were deployed during l week, September 3-10, 2003 with non-baited traps as control. The layout consisted of eight blocks, each containing one trap for each treatment. 


\section{Daily flight pattern}

The study was carried out in a mature vineyard (a collection of different grapevine varieties), at the experimental station of the Regional Agricultural Services of Algarve (ESRASA), Tavira, Portugal, from 28 to 29 June 2005. Male flight activity was monitored based on their capture in 12 pheromone delta traps $(15 \mathrm{~cm} \times 15 \mathrm{~cm} \times 15 \mathrm{~cm})$ of white alveolar polypropylene with $15 \mathrm{~cm} \times 15 \mathrm{~cm}$ sticky plates. Lures were loaded with $200 \mu \mathrm{g}$ LS. The traps were deployed in June 28th, 65 min after sunset, at 10:00 p.m. The sticky plates were substituted before the sunrise of June 29th at 5:00 a.m., $73 \mathrm{~min}$ before sunrise. After this first male count for determining the existence of male flight during the night, traps were checked every hour until 10:00 p.m. of June 29th. Mean air temperature, relative humidity and wind velocity was determined based on records from the automatic meteorological station of ESRASA, ca. $200 \mathrm{~m}$ from the study plot. Light intensity in the plot was measured using an Extech Mod. 407026 light meter.

\section{Seasonal male flight and vine plant infestation}

Information on the study plots is presented in table 1. Seasonal flight activity of the males was recorded from March 2002 to January 2004 in Sde Eliyahu, Geshure-1 and Lachish-1, Israel, and from March 2003 to January 2004 in Jardena, Geshure-2 and Lachish-2, Israel. Five traps, baited with dispensers loaded with $50 \mu \mathrm{g}$ of racemic LS were deployed every month during the 2 nd and 3rd weeks. In each trapping period, clean traps and fresh dispensers were used. Sampling of the mealybug density on the plants was conducted in all six plots in mid-February, late April, late June, early August, mid-October and mid-December of 2003. The density of the mealybugs (from second instar larva to ovipositing females) on the stem and arms, on leaves and bunches was recorded on each visit. Each sample consisted of six counts of 5 min for each of the plant parts, performed by two persons (three counts per person). The mealybug density on the leaves and bunches for each 5-min period was the total number of individuals found during the search. The mealybug density on stems and arms was determined by removing the bark until the first colony of mealybugs was intercepted and the number of mealybugs (as mentioned earlier) was determined. The sampler turned to another vine if after $15 \mathrm{~s}$ no mealybug was found. Two values were considered: the total number of mealybugs found during the 5-min search and the percentage of infested stems. Correlation between the highest mealybug density, on the stem in late June, and maximum male capture in April (Jordan Valley plots) and in May (Lachish and the Golan plots) was calculated.

\section{Comparison of male capture with the two} enantiomers of LS and the racemic material

Male capture in traps baited with lures of $100 \mu \mathrm{g}$ (S)-LS, $100 \mu \mathrm{g}$ (R)-LS and $200 \mu \mathrm{g}$ LS was compared. The traps were deployed from May 4-20, 2004 in Lachish. Each treatment consisted of eight replicates.

\section{Effect of LI on male capture with LS}

In the first experiment, 10, 20, 50 and $100 \mu \mathrm{g}$ of LI were added to lures of $200 \mu \mathrm{g}$ LS and the trap capture was compared with that of lures of $200 \mu \mathrm{g}$ LS and $200 \mu \mathrm{g}$ LI alone. In the second experiment, 100 and $200 \mu \mathrm{g}$ LI were added to lures of $100 \mu \mathrm{g}$ LS and the trap capture was compared with that of lures of $100 \mu \mathrm{g}$ LS and $200 \mu \mathrm{g}$ LI alone. Both experiments consisted of eight replicates per treatment. The tests

\begin{tabular}{|c|c|c|c|}
\hline Area & Location & $\begin{array}{l}\text { Grapevine } \\
\text { variety }\end{array}$ & Type of pest management \\
\hline \multirow[t]{2}{*}{ Jordan Valley } & Sde- Eliyahu & Superior & Organic farm \\
\hline & Jardena & Superior & $\begin{array}{l}\text { Chemical control: 5-6 treatments with organophosphates } \\
\text { throughout the warm season }\end{array}$ \\
\hline \multirow[t]{2}{*}{ Golan } & Geshur (1) & $\begin{array}{l}\text { White } \\
\text { Sauvignion }\end{array}$ & $\begin{array}{l}\text { IPM, soil application of Confidor (Imidacloprid) as a response } \\
\text { to elevation in VM population }\end{array}$ \\
\hline & Geshur (2) & $\begin{array}{l}\text { White } \\
\text { Sauvignion }\end{array}$ & $\begin{array}{l}\text { Chemical control: soil application of Confidor and 1-2 } \\
\text { treatments with organophosphates }\end{array}$ \\
\hline Judean Foot & Lachish (1) & Superior & Organic farm \\
\hline Hills & Lachish (2) & Superior & Chemical control: soil application of Confidor \\
\hline
\end{tabular}

Table 1 Information on the vineyards where the trends of the seasonal male flight and the vine plant infestation were tested 
were conducted in Gshur from August 22 to September 10, 2003 and in Jehonathan vineyard from July 28 to 9 August, 2004, respectively.

Effect of the two enantiomers of LI on the attractiveness of (S)-LS

The capture of males in traps baited with lures of $50 \mu \mathrm{g}$ of (S)-LI and (R)-LI alone and as an addition to $50 \mu \mathrm{g}$ (S)-LS was compared with the capture of $50 \mu \mathrm{g}$ (S)-LS. The test was repeated twice, the first experiment was conducted in Odem in September 13-26, 2004 and the second in Ein Zivan from September 19 to October 10, 2005. Each experiment consisted of eight replicates per treatment.

\section{Effect of the two enantiomers of lavandulol on male} capture

The male capture using baits of $50 \mu \mathrm{g}$ of (S)-lavandulol and (R)-lavandulol alone and as an addition to $50 \mu \mathrm{g}$ of (S)-LS was compared with the capture with baits of $50 \mu \mathrm{g}(\mathrm{S})$-LS. The test was conducted in Odem in September 13-26, 2004 (Test A) and was repeated on the same site from August 15 to September 5, 2004 (Test B). Each experiment consisted of eight replicates per treatment.

\section{Data analysis}

The differences between mean densities of mealybug males per trap and infestation levels per location and dates were tested by a parametric one-way ANOva, applied by means of the PROC GLM, and PROC MEAN software (SAS Institute, 2002); the least sum of squares was used for computing all F-values. Means $(x+0.5)$ were square-root transformed to stabilize the variances. Percentages were transformed to arcsines. Differences between means were tested by the Student-Neuman-Keuls (SNK) procedure. The relationship between peak mealybug density on the stem in late June and peak male capture of VM in May in Lachish and the Golan plots, and in April in the Jordan Valley plots, was determined by linear regression analysis based on data from data obtained in six vineyards in Israel in 2003.

\section{Results}

\section{Lure longevity}

The effect of aging of lures loaded with $200 \mu \mathrm{g}$ of LS on male capture is presented in fig. 1 . A clear effect

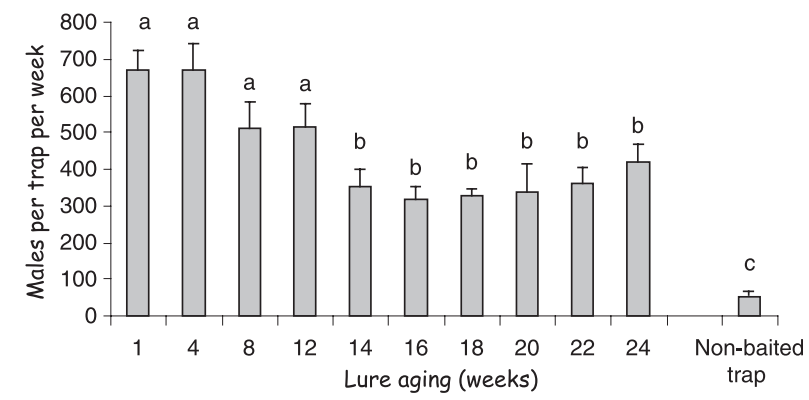

Fig. 1 The effect of aging of lures loaded with $200 \mu \mathrm{g}$ of racemic lavandulyl senecioate on trapping of the vine mealybug males (Gshur, September 2003).

of aging on capture $\left(\mathrm{F}_{9,56}=10.826, \mathrm{P}<0.001\right)$ was observed. There was no significant difference of male capture between fresh, 4-, 8- and 12-week-old lures with an average of $590.5 \pm 77.2$ males per trap per week, and between 14-, 16-, 18-, 20-, 22- and 24week-old lures with an average of $355.9 \pm 32.9$ males per trap per week. However, the older lures attracted significantly fewer males than the fresh ones. Mean male capture per trap per week in control traps, was $53.0 \pm 9.2$, significantly lower that with any of the aged lures.

\section{Daily flight pattern}

Figure 2 shows the daily flight activity of VM males in vineyards in Algarve, Portugal, and displays the climatic conditions, relative humidity and temperature during the experiment. Males started flying after sunrise and about $88 \%$ of the males were trapped from the second to forth hour after sunrise. Only 5\% of the males were captured between 10:00 and 12:00 a.m. and no captures were observed from

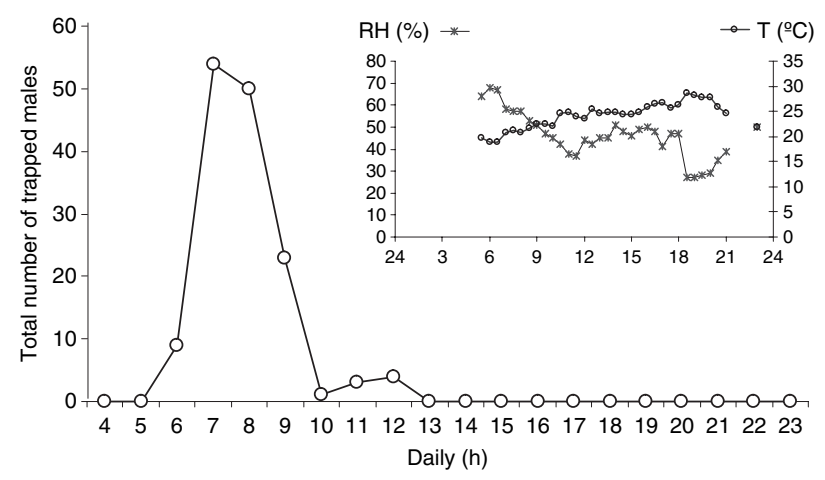

Fig. 2 The daily flight of the vine mealybug males in vineyards in Algarve, Portugal (28 to 29 of June 2005); the imbedded figure displays the trend of the climatic condition during the experiment. 
noon to next dawn, as well as during the night. During the observations, the minimum temperature recorded in the early morning ( $\sim 6: 00$ a.m.) was $18.80^{\circ} \mathrm{C}$ and rose to a maximum of $28.70^{\circ} \mathrm{C}$ at $\sim 6: 30$ p.m. The relative humidity ranged from $27 \%$ in the evening to a maximum of $68 \%$ in the morning at $\sim 6: 00$ a.m. The mean wind velocity was the lowest at in the early morning and the highest in the afternoon, 0.9 and $5.3 \mathrm{~m} / \mathrm{s}$, respectively. Ranges of maximum and minimum wind velocity were 3.0-5.0 and $0.9-2.0 \mathrm{~m} / \mathrm{s}$, respectively.

\section{Seasonal male flight and vine plant infestation}

The seasonal pattern of male flight in the Golan and Judean Hills differed from that in the Jordan Valley (fig. 3). In the cooler mountain areas, a gradual increase of capture was recorded from April with a peak in mid-summer. Capture ceased completely in the cold period of December to February. In the Jordan Valley, peak flight activity was recorded in early summer and in autumn. A sharp decrease in capture was observed in the hottest period (July-August) and in the coldest period (January-February). Trapping pattern was recorded in vineyards under different management, viz., Integrated Pest Management (IPM) or organic vs. chemical control. The mealybug infestation was observed on all the above-ground parts of the vine and also small numbers on main roots. The overall mean mealybug density (mealybug per a 5-min search) on the stem and arms (fig. 4a) was low in mid-February $7.9 \pm 1.5$, and the highest in June $33.9 \pm 25.0$; and decreased to its lowest level in mid-December $5.3 \pm 3.8$. The trend of the seasonal mean percentage of infested stems (fig. 4b) was similar to that of the mealybug density. Although in late June, four (out of six) of the plots revealed 68$97 \%$ infestation, in the two other plots only $36 \%$ of the vines were infested. No clear effect of different managements was revealed by the level of mealybug density; both extremes were displayed in the chemical control plots. The results showed a significant and positive correlation (fig. 5) between the highest mealybug density on the stem in late June and maximum male capture in May in the Judean Hills and the Golan and in April in the Jordan Valley.

Comparison of male capture using baits of chiral (S)-LS and (R)-LS with racemic LS

The number of males captured in traps baited with $100 \mu \mathrm{g}(\mathrm{S})$-LS was the same as that obtained in traps baited with $200 \mu \mathrm{g}$ LS. Traps baited with $100 \mu \mathrm{g}$ (R)-LS captured only a few males, not significantly different from the number of males in the control (fig. 6).

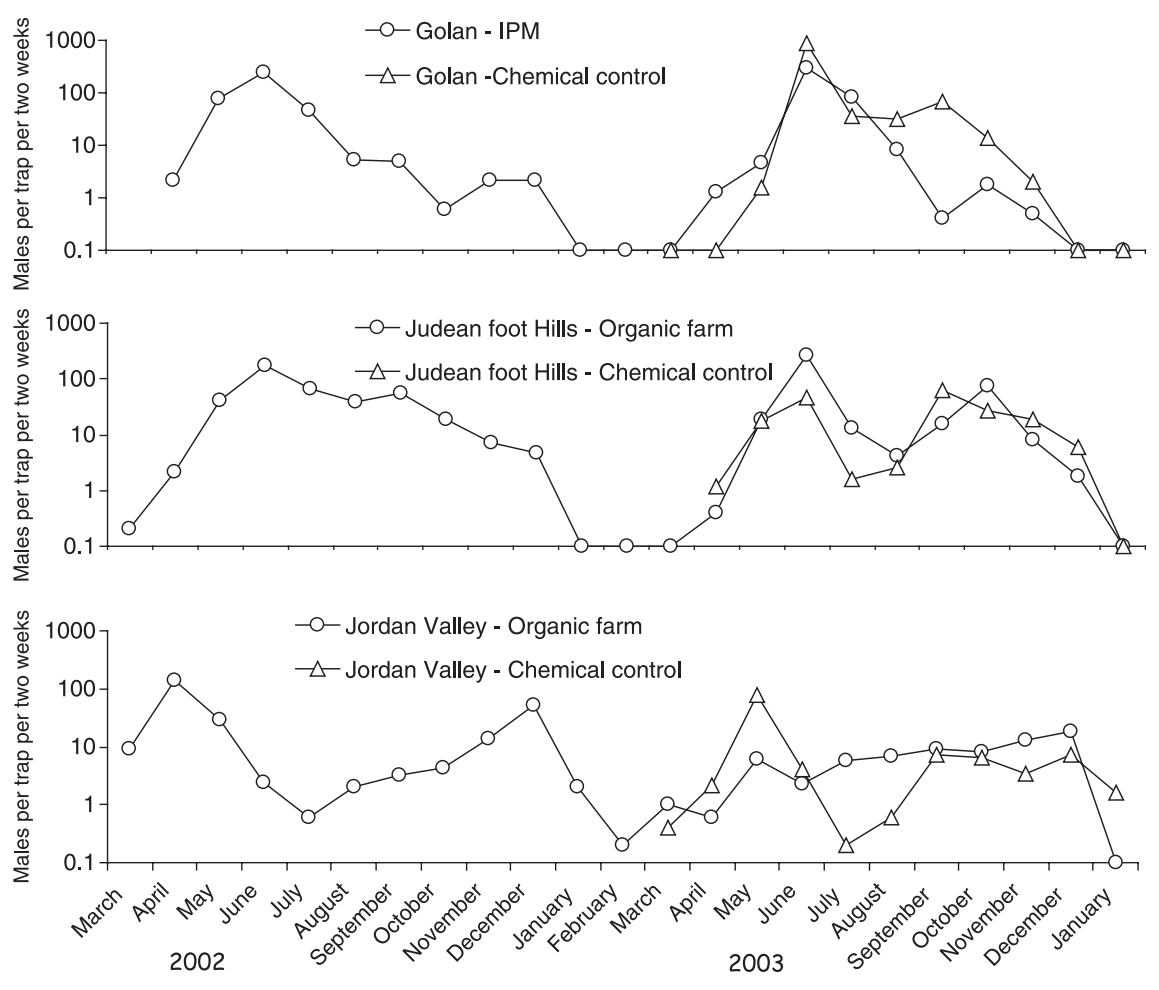

Fig. 3 Seasonal flight of the vine mealybug males in six vineyards in Israel in 2002-2003. 

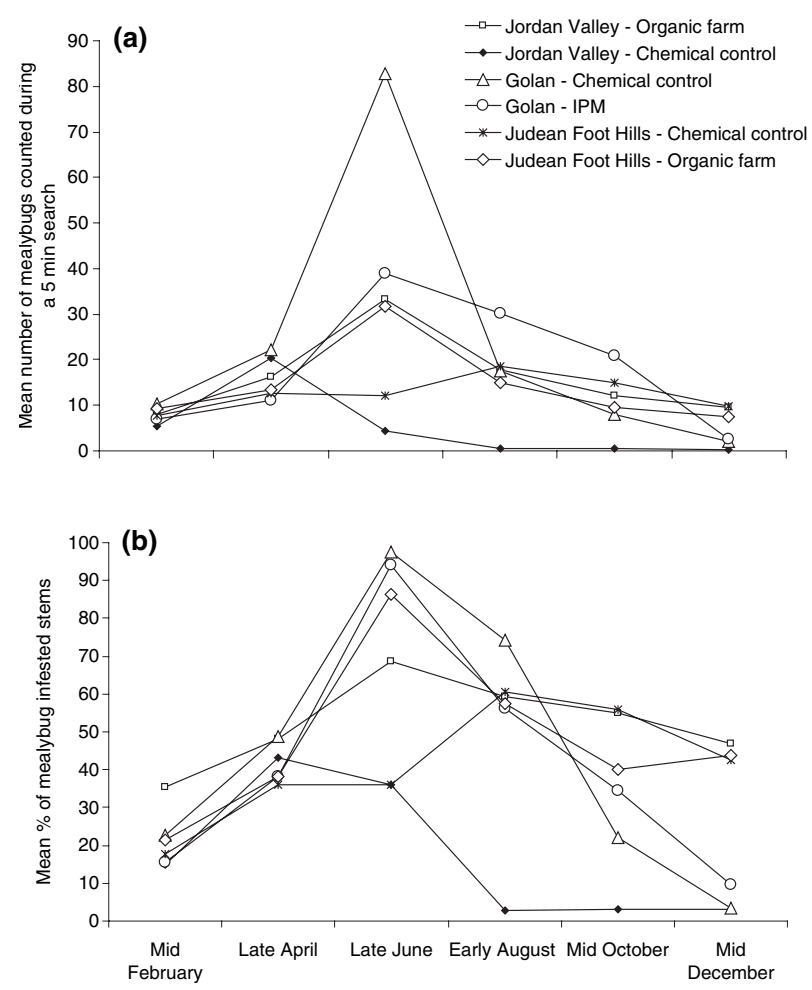

Fig. 4 (a) Seasonal trends of the density and (b) percentage of infested stems of the vine mealybug in six vineyards in Israel in 2003.

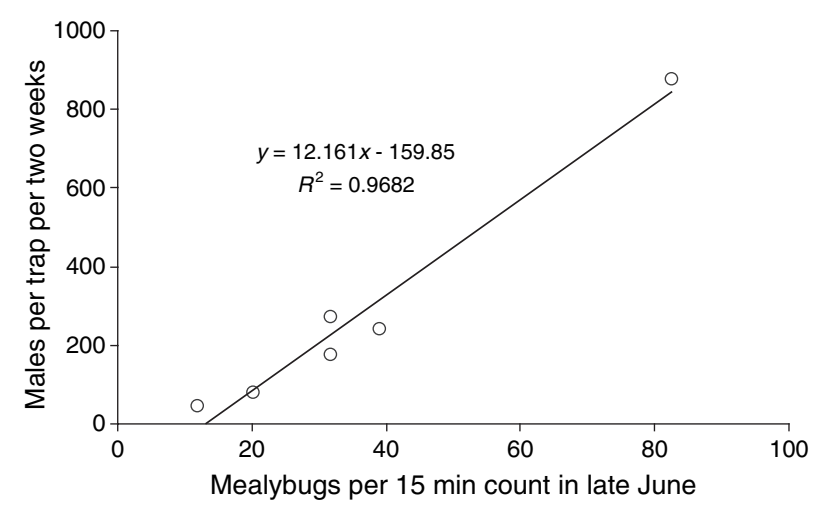

Fig. 5 Relationship between peak mealybug density on the stem in late June and peak male capture of the vine mealybug in May in Lachish and the Golan plots, and in April in the Jordan Valley plots, in six vineyards in Israel in 2003. The traps were baited with $50 \mu \mathrm{g}$ racemic lavandulyl senecioate $(P=0.0027)$.

Effect of LI on the attractiveness of LS and of (S)-LI and $(\mathrm{R})$ - $\mathrm{LI}$ on the attractiveness of (S)-LS

Addition of LI to LS decreased the male capture in two experiments that were conducted in 2003 and 2004. In the first test (fig. 7a), a very strong inhibitory effect was obtained with a decrease of $50 \%$ of

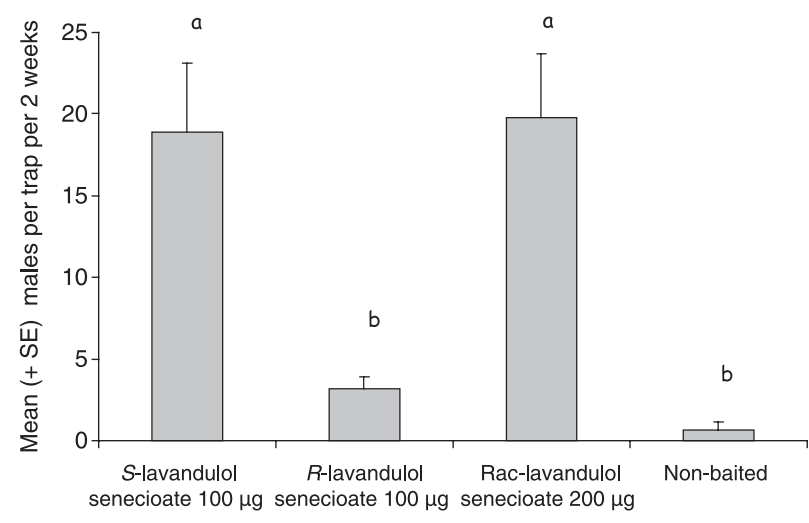

Fig. 6 Capture of the vine mealybug males in traps baited with lures of (S) and (R) enantiomers of lavandulyl senecioate (LS) when compared with racemic LS. Lachish, May 4-22 2004. Values of columns with a similar letter do not differ significantly (SNK test, $P=0.05$ ).

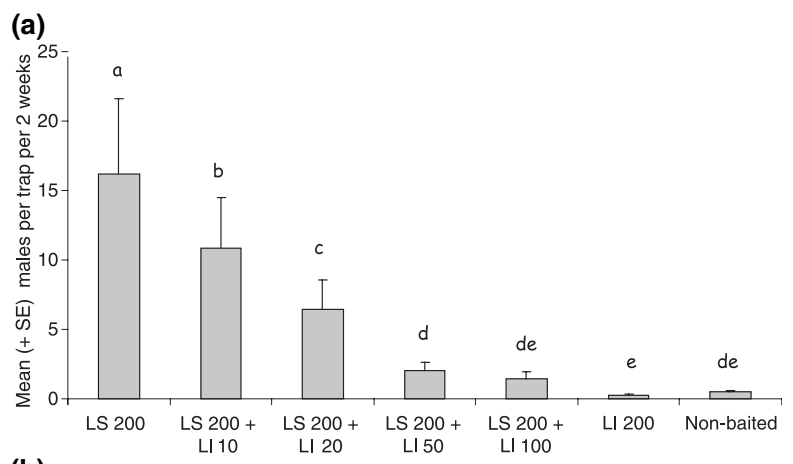

(b)

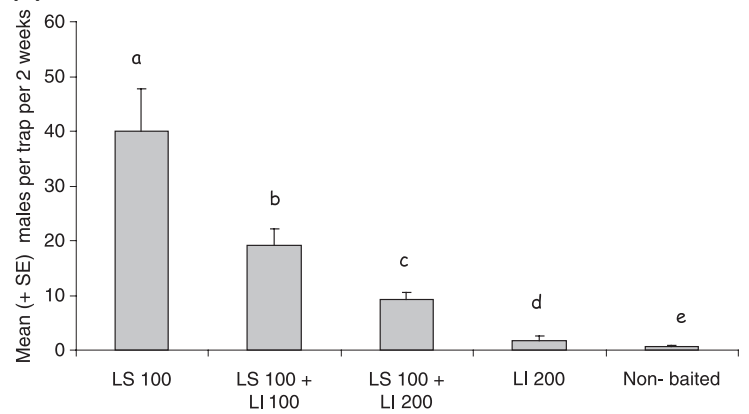

Fig. 7 The effect of racemic lavandulyl isovalerate (LI, $\mu \mathrm{g})$ on the capture of the vine mealybug males, alone and as an addition to racemic lavandulyl senecioate (LS, $\mu \mathrm{g}$ ). (a) Gshur, from August 22 to September 10, 2003; (b) Jehonatan, from July 28 to August 9, 2004. Values of columns with a similar letter do not differ significantly (SNK test, $P=0.05)$.

captured males with only $10 \%$ of LI to LS. In the second test (fig. 7b), a moderate inhibitory effect was observed and a $50 \%$ decrease in male capture was achieved only with the addition of $100 \%$ of LI to LS. Male capture per trap per 2 weeks decreased from a maximum of 16.2 to 1.5 and from 39.6 to 9.2 


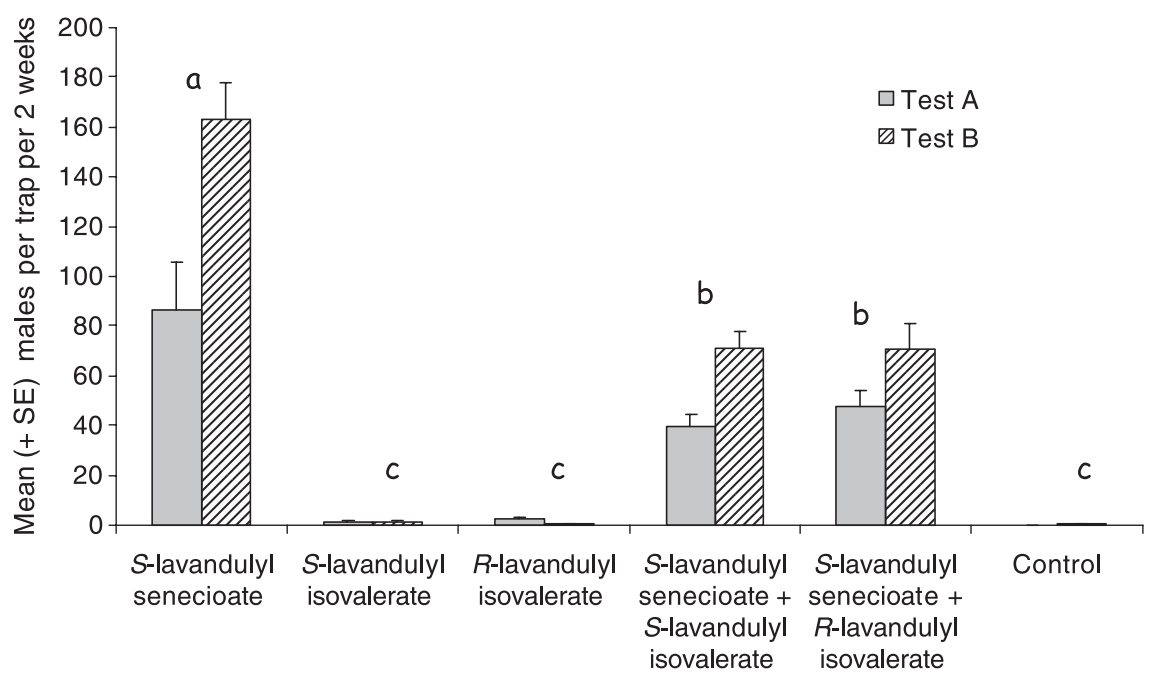

Fig. 8 The effect of the enantiomers of lavandulyl isovalerate, alone and as an addition to (S)-lavandulyl senecioate, on the capture of the vine mealybug males. Lures were impregnated with $50 \mu \mathrm{g}$ of each compound. Test A: Odem, September 13-26, 2004; Test B: Ein Zivan, September 19 to October 10, 2005. For both tests, values of columns with a similar letter do not differ significantly (SNK test, $\mathrm{P}=0.05$ ). by adding $100 \mu \mathrm{g}$ and $200 \mu \mathrm{g}$ LI, in the first and second experiments, respectively (fig. 7). The activity and the impact of (S)-LI and (R)-LI on the attractiveness of (S)-LS were evaluated in two tests. Both enantiomers had no attractive activity (similar to the control) but displayed a similar and significant inhibitory effect on the male capture of (S)-LS with a decrease of $45.4 \%$ and $54.8 \%$ in Odem and $43.8 \%$ and $43.5 \%$ in Ein Zivan, respectively (fig. 8).

\section{Effect of (R)- and (S)-lavandulols on male capture with (S)-LS}

The addition of the two enantiomers of lavandulol (at a ratio of $1: 1$ ) to (S)-LS reduced male capture significantly. The influence of the (S)-enantiomer was stronger than that of $(\mathrm{R})$ resulting in a decrease of $98.6 \%$ and $71.8 \%$ in Test $\mathrm{A}$ and $93.8 \%$ and $65.3 \%$ in Test B, respectively (fig. 9).

\section{Discussion}

The present study clearly showed that traps baited with the racemic pheromone (LS) may be a convenient and reliable tool to estimate population densities of VM. The monitoring method of the VM population in Israel was based for decades on tedious stem sampling which included removal of dry bark strips (Mendel and Blumberg 2002). The only available information on population trends of the mealybug was collected in vineyards in the Negev, the southern semiarid area of Israel. The trends of the feeding stages (mainly young and pre-ovipositing females) were characterized by a peak occurring between mid-May and mid-June, followed by a sharp drop during July, and a second smaller peak between October and December followed by a very low density during the winter (Berlinger 1977). Our present findings indicate a similar pattern in other

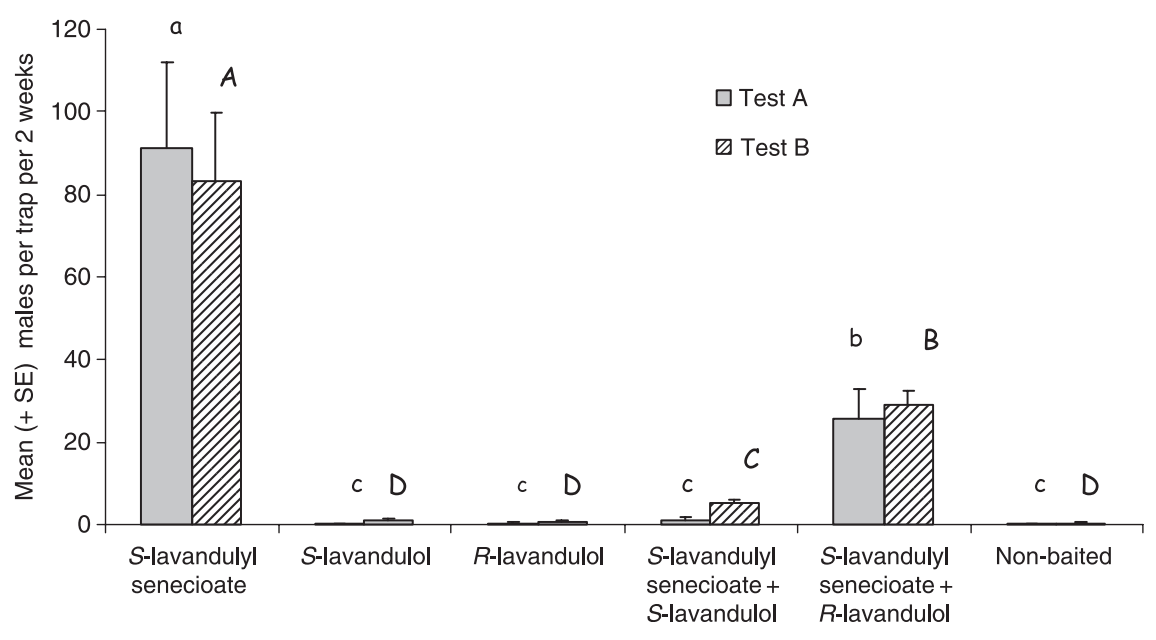

Fig. 9 The effect of the enantiomers of lavandulol on the capture of the vine mealybug males; alone and in addition to (S)-lavandulyl senecioate. The dispensers were loaded with $50 \mu \mathrm{g}$ of each compound. Odem 2004, Test A: from August 15 to September 5; Test B: from September 13-26 2004. Separately for each test, values of columns with a similar letter do not differ significantly (SNK test, $P=0.05$. 
vine growing areas, with minor differences between the different managements. In the present study, the autumn peak was detected only in the male capture. However, in all six studied vineyards, few mealybugs could be found on foliage or bunches. We attribute this pattern of infestation to the fact that in none of the vineyards heavily infested bunches were observed, unlike the high population density studied by Berlinger (1977). In fact, in most samplings, we found less than half of the vines that were infested. Males were captured in pheromone traps throughout the warm season. The trapping pattern consisted of two waves, early summer and autumn to early winter which probably coincides with the periods of high cambium-cortex activity that increase survival of the immature stages. An excellent correlation was found between the infestation and male capture. This observation enhances the potential of pheromone traps as a convenient and reliable tool for monitoring infestation of vineyards by VM. The VM occur in rather similar densities in both organic- and insecticide-treated plots; this was also noticed when the male flight data were examined. The insecticide applications are aimed at the grape berry moth, the honeydew moth and less frequently against leafhoppers and thrips (Avisar 2000; Zehavi 2005). These treatments do not affect the VM populations (Zehavi 2005).

Males of Planococcus citri and Pseudococcus comstocki (Kuwana) are morning crepuscular fliers; flight begins just after sunrise (Moreno et al. 1972, 1984; Ortu and Delrio 1982). Moreno et al. (1984) reported that males of $P$. citri start flight activity at dawn and early morning when light intensity was ca. 1.1 lux. Conversely, Pseudococcus calceolariae (Maskell) males resume flight in the evening (Rotundo and Tremblay 1976; Moreno et al. 1984) suggested that the dial cycle of $P$. citri male flight activity is determined by the scotophase period and is onset in response to exposure to light. Apparently, the VM displays as similar dial cycle of male flight activity as P. citri. Our findings clearly show that the VM males fly in the relatively still air in early morning, when the temperature is low and the relative humidity is higher than in the afternoon. It seems that the males avoid flying at higher wind conditions later in the day. This information will be useful for further studying the use of the female sex pheromone for the management of the VM.

Both, the American (West) and Israeli (Yogev) dispensers are suitable for the preparation of lures use for several weeks. The American dispensers were selected for testing the longevity of the lures for several months in view of our experience of their uniform and extended attractiveness with the citrus mealybug pheromone (Zada et al. 2004). Lures loaded with $200 \mu \mathrm{g}$ LS could be used for monitoring for 24 weeks. However, for more precise information, it is recommended to replace them after 12 weeks.

The natural pheromone of VM is (S)-LS. The opposite enantiomer, (R)-LS, is inactive, being neither an inhibitor nor a synergist. The very low attractiveness of (R)-LS is due to a few percent of remaining (S)-LS in (R)-LS derived from the enzymatic separation of racemic lavandulol and subsequent esterification (Zada and Harel 2004; Zada and Dunkelblum 2006). This recognition pattern has been observed for almost all chiral sex pheromone components of scale insects, indicating that males are indifferent to the unnatural enantiomers of their sex pheromone components (Dunkelblum 1999; Millar et al. 2005). There is one unique case of the pink hibiscus mealybug pheromone in which an antagonistic effect of the unnatural stereoisomer was observed (Zhang et al. 2006). However, this pheromone, comprising two components, has two chiral centres both in the alcohol and in the acidic portions. The critical chiral centre for olfactory discrimination is located in the acidic moiety. In contrast, the other mealybug pheromones (all are esters) have the asymmetric centre only in the alcohol moiety (Dunkelblum 1999; Millar et al. 2005) and their unnatural stereoisomers do not display any antagonistic property. Recently, inhibition of the passionvine mealybug sex pheromone, (E)-2-isopropyl-5methyl-2,4-hexadienyl acetate by its geometrical isomer, (Z)-2-isopropyl-5-methyl-2,4-hexadienyl acetate, has been reported (Ho et al. 2007). However, this is not a chiral system as the other mealybug pheromones.

Previous results revealed that racemic LS attracts very efficiently males of VM (Millar et al. 2002; Zada et al. 2003) and racemic LI is inactive in the field (Zada et al. 2003). The present results confirm that feral VM males are generally not attracted by LI, contrary to laboratory reared males (Zada et al. 2003). Furthermore, addition of small amounts of LI reduced the trap capture significantly. However, the inhibitory effect recorded in the 2003 test was much higher than that obtained in the 2004 experiment. This difference in response may be due to the varying composition of the VM populations in the field. In a further study, when VM males, sons of gravid females collected in several vineyards in Israel, were 
characterized by their response (attraction, rejection or indifference) to LS and LI, several male pherotypes (pherotype $=$ conspecific males that differ in their response to different pheromone components) were observed. In two of the studied vineyards, about half of the tested individuals belonged to a group of males that were attracted to both LS and LI or to LI alone (Kol-Mimon et al. 2007; Mendel et al., unpublished results). These findings suggest that there are feral pherotypes $P$. ficus populations in Israel. This interesting and unusual phenomenon is under investigation in the laboratory and in different vineyards.

The inhibitory effect of the two enantiomers of LI was clearly shown to be the same. The males do not differentiate between the two enantiomers of LI. The inhibition is due to the replacement of the senecioyl function by the isovaleryl one and not by the chirality of the lavandulyl moiety. The intrinsic antagonistic property is due to the different chemical structure of the acidic moieties and not the chirality of the alcohol part.

It is interesting to note that the chirality of lavandulol has a significant impact on its inhibitory effect. It is known that racemic lavandulol, at high dosages, is inhibitory as observed in California (Millar et al. 2002). We tested the two enantiomers separately. (S)-lavandulol was found to be a strong inhibitor, addition of it to the pheromone, (S)-LS, resulted in a complete shut-down of the traps. The inhibitory effect of (R)-lavandulol is moderate, part of it may be due to the presence of about $2 \%$ of (S)-lavandulol in the sample. The results of the tests indicated that the inhibitory effect of (S)-lavandulol is much stronger than that of $(\mathrm{R})$-lavandulol. This is a special case of a moderate, but significant chiral discrimination of an antagonist which is probably the precursor of the pheromone components of VM.

\section{Acknowledgements}

We thank Tirtza Zehavi from the extension service of the Ministry of Agriculture and Rakefet Sharon from North R\&D for the assistance in locating the study vineyards, and to many growers in Israel and Portugal for their valuable co-operation. We also thank Miriam Harel for the laboratory assistance. The research was partly supported by the fund no. 131-1186 of chief scientist of Israeli Ministry of Agriculture and in part also by Fundação para a Ciência e Tecnologia (FCT) and co-funded by FEDER, as part of the Project n. POCI/AGR/57580/2004. JCF received a grant from FCT (SFRH/BSAB/645/2006).

\section{References}

Avisar E, 2000. Control of the vine mealybugs in a vineyard in Lakhish. Unpublished Report submitted to the MoA of Israel for label registration by Lidorr Chemicals Ltd. 2 pp.

Baum D, 1986. Field trials for controlling the European grape berry moth (Lobesia botrana Schiff.) and the honeydew moth (Cryptoblabes gnidiella Mill.) in vineyards. Alon HaNotea. 40, 795-799 (Hebrew, with English abstract).

Ben-Dov Y, 1994. A systematic catalogue of the mealybugs of the world (Insecta: Homptera: Coccoidea: Pseudoccocidae and Putoidae) with data on their geographical distribution, host plants, biology and economic importance. Intercept, Andover.

Berlinger MJ, 1977. The Mediterranean vine mealybug and its natural enemies in southern Israel. Phytoparasitica 5, 3-14.

Bierl-Leonhardt BA, Moreno DS, Schwarz M, Fargerlund J, Plimmer JR, 1981. Isolation, identification and synthesis of the sex pheromone of the citrus mealybug, Planococcus citri (Risso). Tetrahedron Lett. 22, 389-392.

Cox JM, 1989. The mealybug genus Planococcus (Homoptera: Pseudococcidae). Bull. Br. Mus. Nat. Hist. (Entomol.) 58, 1-78.

Daane KM, Bentley WJ, Walton VM, Malakar-Kuenen R, Yokota GY, Millar JG, Ingels CA, Weber EA, Gispert C, 2006. Sustainable controls sought for the invasive vine mealybug. Calif. Agric., 60, 31-38.

Dunkelblum E, 1999. Scale insects. In: Pheromones of non-Lepidopteran insects associated with agricultural plants. Ed. by Hardie J, Minks AK, CAB International, Wallingford, 251-276.

Gill R, 1994. Vine mealybug. California Plant Pest and Disease Report, January-June, 8.

Gordon D, Zahavi T, Anshelevich L, Harel M, Ovadia S, Dunkelblum E, Harari AR, 2005. Mating disruption of Lobesia botrana (Lepidoptera: Tortricidae): effect of pheromone formulations and concentrations. J. Econ. Entomol. 98, 135-142.

Harari AR, Gordon D, Anshelevich L, Zahavi T, Rosenfeld G, Reved R, 2007. Male mating disruption techniques lead to a redaction in chemical applications in controlling the European berry moth in table grapes. Alon HaNotea 61, 12-15 (in Hebrew).

Hinkens DM, McElfresh JS, Millar JG, 2001. Identification and synthesis of the sex pheromone of the vine mealybug, Planococcus ficus. Tetrahedron Lett. 42, 1619-1621.

Ho HY, Hung CC, Chuang TH, Wang WL, 2007. Identification and synthesis of the sex pheromone of the passionvine mealybug, Planococcus minor (Maskell). J. Chem. Ecol. 33, 1986-1996. 
Kol-Mimon H, Zada A, Dunkelblum E, Protasov A, Assael F, Eliyho M, Franco JC, Mendel Z. 2007. Male pherotypes in Mediterranean vine mealybug Planococcus ficus. Abstract of presentation presented at XI International Symposium on Scale Insect Studies, 24-27 September 2007, Oeiras, Portugal.

Mendel Z, Blumberg D, 2002. The vine mealybug Planococcus ficus (Signoret). In: Plant pests of the Middle East. URL http://www.agric.huj.il/mepests. Ed. by Appelbaum SW, Gerson UA, Hebrew University of Jerusalem, Jerusalem, Israel, 1-4.

Millar JG, Daane KM, McElfresh JS, Moreira JA, Malakar-Kuenen R, Guillen M, Bentley WJ, 2002. Development and optimization of methods for using sex pheromone for monitoring the mealybug Planococcus ficus (Homoptera: Pseudococcidae) in California vineyards. J. Econ. Entomol. 95, 706-714.

Millar JG, Daane KM, McElfresh JS, Moreira JA, Bentley WJ, 2005. Chemistry and application of mealybug sex pheromones. In: ACS Symposium Series \#906. Semiochemicals in pest management and alternative agriculture. Ed. by Petroski RJ, American Chemical Society, Washington, DC, 11-27.

Moreno DS, Reed DK, Shaw JG, Newell IM, 1972. Sex lure survey trap for Comstock mealybug. Citrograph 58, 43.

Moreno DS, Fargerlund J, Ewart WH, 1984. Citrus mealybug (Homoptera: Pseudococcidae): behaviour of males in response to sex pheromone in laboratory and field. Ann. Entomol. Soc. Am. 77, 32-38.

Ortu S, Delrio G, 1982. Observations on the field use of the synthetic sex pheromone of Planococcus citri (Risso) (Homoptera, Coccoidea). Redia 65, 341-353.

Rotundo G, Tremblay E, 1976. Osservazioni sull attivita di volo dei maschi di Pseudococcus calceolariae (Mask.) (Homoptera: Coccoidea). Boll. Lab. Entomol. Agrar., F. Silvestri Portici 33, 108-1 12.

SAS Institute, 2002. SAS/STAT User's guide, version 6.11. SAS Institute, Cary, NC. Vol. $1+2$.
Tanne E, Ben-Dov Y, Raccah B, 1989. Transmission of the corky-bark disease by the mealybug Planococcus ficus. Phytoparasitica 17, 55.

Walton VM, Daane KM, Pringle KL, 2004. Monitoring Planococcus ficus in South African vineyards with sex pheromone-baited traps. Crop Prot. 23, 1089-1096.

Walton VM, Daane KM, Bentley WJ, Millar JG, Larsen TE, Malakar-Kuenen R, 2006. Pheromone-based mating disruption of Planococcus ficus (Hemiptera: Pseudococcidae) in California Vineyards. J. Econ. Entomol. 99, 1280-1290.

Zada A, Dunkelblum E, 2006. A convenient resolution of racemic lavandulol through lipase-catalyzed acylation with succinic anhydride: simple preparation of enantiomerically pure (R)-lavandulol. Tetrahedron Asymmetry 17, 230-233.

Zada A, Harel M, 2004. Enzymatic transesterification of racemic lavandulol: Preparation of the two enantiomeric alcohols and of the two enatiomers of lavadulyl senecioate, the sex pheromone of the vine mealybug, Planococcus ficus. Tetrahedron Asymmetry 15, 2339-2343.

Zada A, Dunkelblum E, Assael F, Harel M, Cojocaru M, Mendel Z, 2003. Sex pheromone of the vine mealybug, Planococcus ficus, in Israel: occurrence of a second component in a mass-reared population. J. Chem. Ecol. 29, 977-988.

Zada A, Dunkelblum E, Harel M, Assael F, Gross S, Mendel Z, 2004. Synthesis and optimization of trap parameters for the use of the sex pheromone of the citrus mealybug. J. Econ. Entomol. 97, 361-368.

Zehavi T, 2005. Identification and control of vineyard pests. Extension Service Publications, Ministry of Agriculture and Rural Affairs (in Hebrew), Bet-Dagan, Israel. No. 1353, 64 pp.

Zhang A, Wang Sh, Vitullo J, Roda A, Mannion C, Bergh JCh, 2006. Olfactory discrimination among sex pheromone steroisomers: chirality recognition by pink hibiscus mealybug males. Chem. Senses 31, 621-626. 
Copyright of Journal of Applied Entomology is the property of Blackwell Publishing Limited and its content may not be copied or emailed to multiple sites or posted to a listserv without the copyright holder's express written permission. However, users may print, download, or email articles for individual use. 